\title{
Association of Positive Psychological Wellbeing and BMI with Physical and Mental Health among College Students
}

\author{
Weiyun Chen ${ }^{1 *}$, Miaolin Hua ${ }^{5}$, Shouwen $\mathrm{Yu}^{2}$, Xiaozan Wang ${ }^{3}$ and Dale Ulrich ${ }^{4}$ \\ ${ }^{1}$ Associate Professor School of Kinesiology, University of Michigan, USA \\ ${ }^{2}$ Department of Physical Education, Fudan University, China \\ ${ }^{3}$ Professor School of Physical Education and Health East, China Normal University, China \\ ${ }^{4}$ Professor School of Kinesiology, University of Michigan, USA \\ ${ }^{5}$ Associate Professor, Department of Physical Education, East China University of Political Science and Law, Shanghai, China
}

Received: September 05, 2017; Published: September 20, 2017

*Corresponding author: Weiyun Chen, Associate Professor School of Kinesiology, University of Michigan 1402 Washington Heights, Ann Arbor, MI 48109, USA, Tel: 734-615-0376; Fax: 734-764-8325; Email: chenwy@umich.edu

\section{Abstract}

Purpose: This study examined the extent to which Body Mass Index (BMI) and four positive personal attributes (hope, gratitude, life satisfaction, and subjective happiness) contributed to physical and mental health in university students.

Methods: Participants were 925 university students (591 males vs. 334 females; Mean age $=19.66 \pm 1.43$ years old) in a major public university in Shanghai. The students completed the physical and mental health survey modified from 2013 and 2015 National Youth Risk Behavior Surveys, the Hope Scale, the Gratitude Questionnaire-6 (GQ-6), the Satisfaction with Life Scale (SWLS), the Subjective Happiness Scale, and the self-reported body height and weight used for computing BMI in regular physical education classes. Alpha coefficients of each measure ranged from .83 to .90. Data were analyzed using descriptive statistics, multiple R-squared linear regression models, MANOVA, and ANOVA as well as post hoc comparisons.

Results: BMI and the four positive personal attributes significantly predicted physical and mental health $(\mathrm{F}=127.21, \mathrm{p}<.01)$, accounting for $41 \%$ of the total variance in health. The standardized regression coefficients $(\beta)$ revealed that BMI, hope, and subjective happiness were individual, significant contributors to health $(\mathrm{t}=-3.72, \mathrm{t}=8.01, \mathrm{t}=12.02, \mathrm{p}<.01)$. Students in higher levels of the health groups scored significantly higher in hope, gratitude, life satisfaction, and subjective happiness than their counterparts in the two lower quartiles.

Conclusion: Healthy body weight and positive personal attributes play paramount roles in influencing physical and mental health among Chinese university students.

Keywords: Physical well-being; Psychology well-being; Personal positive constructs

Abbreviation: NAMI: National Alliance On Mental Illness; GQ 6: Gratitude Questionnaire-6; BMI: Body Mass Index; SWLS: Satisfaction With Life Scale; IRB: Institutional Review Board; HSBS: Health Sciences and Behavioral Sciences

\section{Introduction}

Anxiety and depression have been documented as top mental health issues that impede college students' academic performance National Alliance on Mental Illness [NAMI] [1]; Pedrelli, Nyer, Yeung, Zulauf, and Wilens, [2]. More than $80 \%$ of college students have felt overwhelmed by college-related tasks and more than $50 \%$ have felt extremely anxious about their academic struggles in the past year. Also, 31\% have felt too depressed to function well in schools NAMI [1]. 64\% college students who had mental health problems withdrew from the university. 50\% did not seek out mental health services and request accommodations NAMI [1]. Given the prevalence and severity of mental health problems faced by college students and their hesitation and reluctance to seek professional mental health services, there is a critical need for exploring an alternative approach to a primary prevention and treatment Seligman \& Csikszentmihalyi [3]; Wood, Froh and Geraghty [4] .

Psychologists and researchers have increasingly advocated that nurturing positive personal attributes and enhancing human strengths and virtues such as subjective well-being, gratitude, and hope play vital roles in determining physical and mental health Emmons \& McCullough [5]; Gilman \& Huebner [6]; Seligman and Csikszentmihalyi [3]; Snyder [7]. Health is referred to the overall state of a person's physical, mental, and social well-being and to the presence or absence of physical and mental illness or injury Fahey, Insel, Roth and Insel, [8]; World Health Organization [WHO] 
[9]. While physical health (physical well-being) and mental health (cognitive and emotional well-being) have their own unique constructs, they are two essential and integral components of health and they are interdependently co-existed Fahey et al. [8]; WHO [9].

Subjective well-being refers to how people think and feel about their life experiences in positive ways Diener, Suh, Lucs, and Smith [10]. Two widely accepted theoretical constructs of subjective wellbeing are the affective or happiness and the judgmental or cognitive component (life satisfaction). Although the two components are related to each other, each has its own unique construct Diener, Suh, Lucs, and Smith [11]; Pavot and Diener 1993. Happiness is defined as an individual's subjective feelings about joy and contentment while viewing and experiencing one's life in a meaningful and worthwhile way Lyubomirsky [12].

The events that occur to make some persons feel happy may cause others to feel indifferent because individuals have varying backgrounds, expectations, pursuits, and interpretations. Each person has his/her own criteria and interpretations of happiness Lyubomirsky [12]. Studies have shown that happiness is positively linked to lower heart rate, better blood pressure, and heart rate variability and negatively associated with coronary heart disease and heart disease risk factors Lyubomirsky, King, \& Diener [13]. Happy people are less likely to get sick and more likely to have a good sleep. Happy people show a better coping skill for stressful situations and enjoy their successful career Dockray \& Steptoe [14]; O' Connor, Crawford and Holder [15].

Life satisfaction refers to "an individual's overall cognitive appraisal of the quality of his/her life" Gilman, Huebner, and Laughlin [6]. Individuals use their own unique criteria to judge what a "good life" is about and use their internal standards to define what "success" means to them in various aspects of life. Accordingly, Pavot and Diener 1993, viewed life satisfaction as one-dimensional construct. Taking an individual's own standards of evaluation into account, Diener, Emmnos, Larsen and Griffin [11] developed The Satisfaction with Life Scale (SWLS) as a self-report measure to assess a person's global life satisfaction.

Studies have revealed positive associations of global life satisfaction with enhanced physical and mental health, selfconcepts, self-esteem, positive life experiences in schools, family, peers, and environments Ash and Huebner [16]; Gilman and Huebner [6]; Gilman, Huebner and Laughlin, 2000. In contrast, dissatisfaction with life has been linked to self-rated poor physical health, depression, anxiety, social isolation, and substance abuse Gilman et al [6]; Zullig, Valois, Huebner, Oeltmann and Drane [17]; Zullig, Valois, Huebner and Drane [18]. Hope is a strength-based personal attribute. According to hope theory, hope is defined as an individual's positive expectation for achieving clearly conceptualized goals through developing strategic pathways and alternative approaches to reaching the goals (pathway thinking) and keeping him/herself motivated to use the strategies for achieving desired goals (Agency thinking) Snyder [19]; Snyder, Feldman, Taylor, Schroeder, and Adams [20]; Snyder, Lopez, Shorey, Rand and Feldman [21].
The two constructs of hope are interrelated and complemented to each other necessary for successful goal pursuit. Accordingly, Snyder, et al. [22] developed the Hope Scale consisting of four items to measure pathways, four items to measure agency, and four distracters. Studies have shown that hope significantly predicts students' academic achievement and successful graduation as well as health-related behaviors Nothwehr, Clark and Perkins [23]; Snyder and Shorey [19]; Snyder et al. [20]. High-hope students have reported better GPA and achievement test scores and greater satisfaction with their academic performance and social interactions. High-hope students have high self-efficacy and selfesteem Onwuegbuzie and Synder [24]; Snyder and Shorey [19]; Snyder et al. [20]. While low-hope students have high anxiety in achievement tests and are prone to quit their goal pursuits when facing barriers and obstacles. Low-hope contributes to more depressive traits Snyder et al. [19]; Snyder et al. [20].

Gratitude is emotional appreciation for receiving others' helpful and valuable actions and dispositional appreciation for the positive in life McCullough, Tsang and Emmons [25]; Wood, Froh and Geraghty [4]. Gratitude is an activating and pleasant state and a joyful and contented emotion Emmons and McCullough [5]. At the dispositional (tendency) level, gratitude is a part of broad life orientation towards thankful responses to events and life experiences Wood et al. [26]. In line with the view of life orientation, McCullough, Emmons, and Tsang 2002 designed the uni-factorial Gratitude Questionnaire-Six Item Form (GQ-6) to measure dispositional gratitude. Studies have shown that grateful people tend to be friendly, optimistic, open-minded, caring, and resilient. Gratitude is strongly related to positive effect, happiness, life satisfaction, and hope Froh, Fan, Emmons, Bono, Huebnerand Watkins, 2011; McCullough et al [27]; McCullough et al. [28].

Studies have shown the links between BMI and psychological well-being. For example, one study found that obesity can contribute to self-rated poor health status, distress, and functional impairment in 1,822 obese outpatients Corica, et al. [29]. Another study reported that among 3,000 adults ages 25-74, obese persons showed higher levels of negative affect compared to persons with lower BMI Carr, Friedman and Jaffe [29]. Further, examining gender, BMI, and psychological well-being of 3,251 adults ages 2574 , the study found that women with higher BMI scored lower in psychology well-being compared to those with the normal weight. In contrast, men did not show any significant differences between BMI and psychological well-being scores Bookwala and Boyar [30].

While studies have shown positive contributions of happiness, life satisfaction, hope, and gratitude to physical and psychological well-being in young adult and adult populations, exploration of the concurrent influence of those positive attributes along with BMI on physical and mental health in university students is scarce. Furthermore, little is known about how these positive attributes along with BMI collectively and individually influence physical and mental health in Chinese university students. Thus, the purposes of this study were twofold:

a. To determine a profile of the university students' physical and mental health, positive personal attributes, and BMI; and 
b. To examine the extent to which the four positive personal attributes (happiness, life satisfaction, hope, gratitude) and BMI contribute to physical and mental health in university students. The significance of this study lies in adding the empirical findings derived from Chinese university student population to the existing literature in positive psychology linking to physical and psychological well-being. The results of this investigation will provide empirical evidence for future intervention strategies that focus on strengthening positive personal attributes and maintaining healthy body weight to prevent physical and mental health problems and to enhance physical and mental health in university students.

\section{Methods}

\section{Participants}

Participants were 1,000 undergraduate students who were enrolled in 21 physical education classes offered in fall semester, 2015 at a major public university in China. The University Institutional Review Board (IRB)-Health Sciences and Behavioral Sciences (HSBS) approved to conduct this study (HUM00102146). The students were informed that they could participate in this study upon returning their signed consent forms to their physical education teachers on the scheduled date. All students indicated their voluntary participation in this study by reviewing and signing the consent form.

Prior to answering a set of questionnaires, the students were assured confidentiality and anonymity by their physical education teachers who were trained in the procedures of administering the questionnaires by one investigator. The trained physical education teachers administered the questionnaires to the students and answered any questions raised by the students during a regular physical education class. The student returned their completed questionnaires to the envelope provided by the teacher during the PE class. Of these students, 75 students were excluded from data analysis because of missing and incomplete data. A total of 925 participants (591 males vs. 334 females) were comprised of the data analysis in this study. The mean age of the participants was $19.66(\mathrm{SD}=1.43)$ years old.

\section{Measures}

\section{Demographic Information and BMI}

The students were asked to complete the demographic information including years of college, age, sex, ethnicity, body height (centimeter), and body weight (kilogram). The self-reported body height and body weight were used to compute body mass index (BMI) using the formula of $\mathrm{kg} / \mathrm{m}^{2}$.

\section{Physical and Mental Health Survey (PMHS)}

The self-rated 11-item PMHS consists of two sub-scales: physical health with 4-items and mental health with 7-items. The four items on the physical health sub-scale were derived and modified from the questions asking about feeling healthy and energy and having good sleep on the 2013 and 2015 Youth Risk Behaviors Survey (YRBS). Seven items on the mental health sub-scale were taken and modified from the questions asking about feeling worthless, fidgety, anxious, and depressed on the 2013 and 2015 YRBS. In this study, the students responded to the items using a 5-point rating scale (5 = always, $4=$ often, $3=$ sometimes, $2=$ seldom, 1 = never). However, all items on mental-health sub-scale were reversely coded when the score of each item was input into the data set for data analysis. In this study, the physical and mental health sub-scales and the total scale of PMHS had accepted internal consistency $(\alpha=.845, .904$, and .872 , respectively).

\section{The Hope Scale}

Snyder et al. [22] developed the 12-item Hope Scale consisting of four items on the sub-scale of Pathways, four items on the sub-scale of Agency, and four distracter items using a 5-point rating scale in youth and adult populations. The four items of the Pathways measure an individual's ability to use effective strategies for reaching the desired goals. The four items on the Agency assess an individual's capacities to motivate him/her for using the strategies to achieve the goals. The composite score of the two subscales represents an index of Hopeful Thought. The Hope Scale has been proven to be a reliable and valid measure to assess two key constructs of hope with adults Snyder et al. [21]. In this study, the alpha correlation coefficients of the Pathways sub-scale, Agency sub-scale, and the total scale were $.829, .828$, and .888 , indicating a good degree of internal consistency.

\section{Gratitude Questionnaire-6 (GQ-6)}

McCullough et al. [27] developed the GQ-6 to assess the dispositional gratitude in adolescents and adult populations. The GQ-6 has possessed good psychometric properties with the population of adolescents and adults McCullough et al. [27]. However, two studies showed that item 6 had a weak and nonsignificant factor loading to the uni-factor based on a confirmatory factor analysis, suggesting the item 6 might be invariant across cultures for assessing dispositional gratitude Chen, Chen, Kee and Tsai [31]; Froh et al. Accordingly, this study removed item 6 from the GQ-6 and asked the students to respond to five items with a 5-point Likert rating scale. The five items of the GQ- 6 had .90 of the alpha correlation coefficient.

\section{The Satisfaction with Life Scale (SWLS)}

Diener et al. [11] developed the 5-item SWLS to assess an individual's global judgment of life satisfaction using the 5-point Likert rating scale. Validation studies have shown that the five items of the SWLS were coherently loaded to one unified factor, suggesting the one-dimensional life satisfaction; the SWLS had moderate temporal stability and showed a good discriminated validity from related emotional constructs of well-being. The reliable and valid SWLS has been used with adolescents, undergraduates, and adults Pavot and Diener 1993. In this study, the students were asked to respond to five items of the SWLS using a 5-point rating scale to assess their global life satisfaction. The alpha value of the SWLS was .890 , confirming a high degree of internal consistency on this unique scale of the SWLS.

\section{Subjective Happiness Scale (SHS)}

Given the personal and subjective nature of happiness, Lyubomirsky and Lepper [32] designed the 4-item Subjective 
Happiness Scale (SHS) with a 7-point Likert scale to assess a person's global subjective experience of happiness. When responding to the 4-items, individuals using their own criteria about happiness and their own interpretations of happiness to indicate how happy or unhappy they are in relation to others Lyubomirsky and Lepper, [32]. Through rigorous testing the internal validity and reliability of the SHS with large samples of high school students, college students, and adults, Lyubomirsky and Lepper [32] reported that the SHS has sound psychometric properties. In this study, the students responded to four items of the SHS using a 7-point Likert rating scale. The SHS had .888 of the alpha value, indicating an acceptable internal consistency.

\section{Translation of the Measures}

All measures in English were translated into Chinese and then translated back into English again for the purpose of this study. Initially, the measures were translated from English into Chinese by a Chinese professor who was a visiting scholar at a major public university in USA and showed a proficiency level in English. Then, the measures translated into Chinese were reviewed and edited by the first author who has been a professor at two universities in USA for 19 years. The first author, as a Chinese-American professor, received K-12 education, undergraduate, and master graduate education in China and obtained Ph.D. degree at a major public university in USA.

Then, the translated measures in Chinese were translated back into English by the first author. Next, the measures in English and in Chinese were sent to five professors who were asked to judge the extent to which each item was accurately translated from English into Chinese using a 5-point rating scale, anchored with $5=$ fully accurate, $4=$ mostly accurate, $3=$ partially accurate, $2=$ rarely accurate, $1=$ not accurate. Among the five professors, three were Chinese-American professors who were bilingual in English and Chinese and two were Chinese professors who had studied at universities in USA for more than a year as visiting scholars and showed a proficiency level in English. They sent their completed measures with specific edits and comments to the first author. Finally, the first author reviewed the professors' judgment and comments on the measures and items edited by the professors to make the final version of the measures in Chinese, which was used in this study.

\section{Data Analysis}

Descriptive statistics were computed for all variables including the health (physical and mental health), hope, gratitude, life satisfaction, subjective happiness, and BMI. To examine the extent to which hope, gratitude, life satisfaction, subjective happiness, and BMI were associated with the health (physical and mental health) in college students; a multiple R-Squared linear regression model was conducted. Further, the mean score of the health (physical and mental health) was computed and was then used to classify the students into four levels of health using percentile values of the quartiles. To examine if there was a significant mean score difference on each of the five dependent variables including hope, gratitude, life satisfaction, subject happiness, and BMI among the four groups (four levels of the health), MANOVA was performed, followed by ANOVAs and post-hoc comparison methods. A significant level of $p$ $<.05$ was set for all statistical methods. All statistical analyses were conducted by means of IBM SPSS statistics version 24 for Windows.

\section{Results}

\section{Descriptive Analysis}

Table 1 presents mean scores and standard deviations of the health (physical and mental health), hope, gratitude, life satisfaction, and subjective happiness by total sample and gender. As seen in Table 1, the average score of the health indicated that students (between sometimes and often) felt healthy and energetic, had a good sleep, and felt satisfied with their body weight on the physical health sub-scale. In contrast, the students self-rated that they (between sometimes and seldom) felt depressed, anxious, restless, and worthless, and had suicide attempt on the mental health sub-scale (Table 1).

Table 1: Means (M) and standard deviations (SD) of students' health and four positive attributes.

\begin{tabular}{|c|c|c|c|c|c|c|c|c|c|c|}
\hline \multirow[t]{2}{*}{ Groups } & \multicolumn{2}{|c|}{ Health } & \multicolumn{2}{|c|}{ Hope } & \multicolumn{2}{|c|}{ Gratitude } & \multicolumn{2}{|c|}{ Satisfaction } & \multicolumn{2}{|c|}{ Happiness } \\
\hline & $\mathbf{M}$ & SD & $\mathbf{M}$ & SD & $\mathbf{M}$ & SD & $\mathbf{M}$ & SD & $\mathbf{M}$ & SD \\
\hline Total & 3.56 & .56 & 3.46 & .67 & 3.96 & .72 & 3.11 & .78 & 5.1 & .90 \\
\hline Males & 3.60 & .56 & 3.51 & .68 & 3.92 & .73 & 3.12 & .81 & 5.14 & .91 \\
\hline Females & 3.49 & .54 & 3.37 & .63 & 4.03 & .70 & 3.09 & .74 & 5.21 & .86 \\
\hline
\end{tabular}

Table 2: Frequencies and Percentage of self-reported overall health and positive psychological well-beings.

\begin{tabular}{|c|c|c|c|c|c|c|c|}
\hline Variables & Rating scales 1 n (\%) & $\mathbf{2} \mathbf{n}(\mathbf{\%})$ & $\mathbf{3} \mathbf{n}(\mathbf{\%})$ & $\mathbf{4} \mathbf{n}(\mathbf{\%})$ & $\mathbf{5 ~ n ~ ( \% )}$ & $\mathbf{6} \mathbf{n}(\mathbf{\%})$ & $\mathbf{7} \mathbf{n}(\mathbf{\%})$ \\
\hline Health & $5(.05)$ & $120(13.0)$ & $529(64.0)$ & $200(21.7)$ & $7(0.8)$ & \\
\hline Hope & $10(1.1)$ & $166(17.9)$ & $549(59.4)$ & $179(19.4)$ & $21(2.3)$ & \\
\hline Gratitude & $5(0.6)$ & $58(6.3)$ & $348(37.6)$ & $388(41.9)$ & $134(14.5)$ & \\
\hline Life Satisfaction & $48(5.2)$ & $318(34.3)$ & $410(44.3)$ & $127(13.7)$ & $22(2.4)$ & & \\
\hline Happiness & & $11(1.2)$ & $46(5.0)$ & $281(30.4)$ & $396(42.8)$ & $159(17.2)$ & $31(3.4)$ \\
\hline
\end{tabular}


Similarly, the proportions of students' self-rated health on each of the 5-point rating scale (Table 2) echoed the mean score of the health. For example, $64 \%$ of the students sometimes and $21.7 \%$ of the students often felt healthy, had good sleep, satisfied with their body weight. Similar to the mean score of the health, $64 \%$ of the students sometimes and $21.7 \%$ of the students seldom felt depressed, anxious, restless, and worthless (Table 2).

Table 3.
The self-reported mean score of BMI was in the normal weight category (BMI: 18.5-24.9) based on the classification of BMI WHO Expert Consultation [9] (Table 3). Further, according to the proportions of BMI categories, $77.2 \%$ of the students' BMI was in the normal weight. Only $13.3 \%$ of the students' BMI was in the underweight category, and $9 \%$ of the students' BMI was in the overweight category (Table 3).

\begin{tabular}{|c|c|c|c|c|c|c|c|c|c|c|}
\hline & \multicolumn{2}{|c|}{ BMI } & \multicolumn{2}{|c|}{ Underweight $(<18.5)$} & \multicolumn{2}{|c|}{ Normal (18.5-24.9) } & \multicolumn{2}{|c|}{ Overweight $(25.0-29.9)$} & \multicolumn{2}{|c|}{ Obese I (30.0-34.9) } \\
\hline & $\mathbf{M}$ & SD & $\#$ & $\%$ & $\#$ & $\%$ & $\#$ & $\%$ & $\#$ & $\%$ \\
\hline Total & 21.9 & 2.72 & 123 & 13.3 & 714 & 77.2 & 83 & 9.0 & 5 & 0.5 \\
\hline
\end{tabular}

As seen in Table 1, the mean scores of the four positive personal attributes indicated moderately high level of hope, gratitude, life satisfaction, and subjective happiness, with the highest average score of gratitude, followed by hope and subjective happiness, and the lowest average score of life satisfaction. Likewise, the proportions of the four positive attributes rated on each of the rating scale (Table 2) mirrored the mean scores of them. As shown in Table 2, 37.6\% of the students reported expressing somewhat gratitude and $41.9 \%$ of the students reported showing mostly gratitude; $59.4 \%$ of the students reported having somewhat hopeful thinking and $19.4 \%$ of the students reported having mostly hopeful

\section{attributes, (Table 4)}

Table 4: Results of the multiple R-squared regression model using BMI and four positive attributes to predict the overall health.

\begin{tabular}{|c|c|c|c|c|c|c|c|}
\hline Samples & $\boldsymbol{R}$ & $R^{2}$ & $R^{2}$ & $p$ & Beta & $t$ & $p$ \\
\hline Model & .64 & 41 & 127.22 & $<.01$ & & & \\
\hline BMI & & & & & -.10 & -3.72 & $<.01$ \\
\hline Hope & & & & & .27 & 8.01 & $<.01$ \\
\hline Gratitude & & & & & .00 & -.01 & $>.05$ \\
\hline Life Satisfaction & & & & & .05 & 1.52 & $>.05$ \\
\hline Happiness & & & & & .40 & 12.02 & $<.01$ \\
\hline
\end{tabular}

Table 5: Quartiles of the overall health in terms of number of each group and descriptive statistics of each health group.

\begin{tabular}{|c|c|c|c|c|c|}
\hline Groups & Percentiles & $\begin{array}{c}\text { Means of the Range } \\
\text { (Minimum-Maximum) }\end{array}$ & N & M & 2.86 \\
\hline 1 & $0-25$ & $1.00-3.18$ & 234 & 3.38 & .34 \\
\hline 2 & $26-29$ & $3.19-3.56$ & 221 & 3.74 & .11 \\
\hline 3 & $50-74$ & $3.57-3.94$ & 237 & 4.24 & .27 \\
\hline
\end{tabular}

Significantly predicted the health $\left(\mathrm{F}_{5,919}=127.21, \mathrm{p}<.01\right)$. These independent variables explained $41 \%$ of the total variance in the health for the total sample. Further, the results of standardized regression coefficients $(\beta)$ indicated that BMI, hope, and subjective happiness were individual significant contributors to the health, while gratitude and life satisfaction did not display significant

thinking; the majority of the students reported feeling happy to feeling almost very happy (42.8\% rating 5 and $17.2 \%$ rating 6 on the 7 -point rating scale). In contrast, $34.4 \%$ of the students reported feeling slightly satisfied with their lives and $44.3 \%$ of the students reported feeling somewhat satisfied with their lives.

\section{Association of BMI and Positive Attributes with Health}

Table 4 illustrates the results of the multiple R-squared linear regression analysis with BMI and four positive personal attributes predicting the health. The results of the regression model indicated that the independent variables, BMI and four positive personal 
Table 6: Means and standard deviations of BMI and the four positive attributes among four health groups.

\begin{tabular}{|c|c|c|c|c|c|c|c|c|c|c|}
\hline \multirow[b]{2}{*}{ Groups } & \multicolumn{2}{|c|}{ BMI } & \multicolumn{2}{|c|}{ Hope } & \multirow[b]{2}{*}{$\mathbf{M}$} & \multirow[b]{2}{*}{ SD } & \multirow[b]{2}{*}{ M } & \multirow[b]{2}{*}{ SD } & \multirow[b]{2}{*}{$\mathbf{M}$} & \multirow[b]{2}{*}{ SD } \\
\hline & & SD & & SD & & & & & & \\
\hline 1 & 21.36 & 2.81 & 3.06 & .63 & 3.74 & .79 & 2.71 & .79 & 4.51 & .89 \\
\hline 2 & 21.34 & 2.67 & 3.33 & .53 & 3.89 & .69 & 2.95 & .64 & 5.00 & .71 \\
\hline 3 & 21.25 & 2.91 & 3.51 & .59 & 3.96 & .67 & 3.18 & .67 & 5.34 & .69 \\
\hline 4 & 20.80 & 2.42 & 3.93 & .59 & 4.24 & .64 & 3.59 & .74 & 5.82 & .72 \\
\hline
\end{tabular}

The results of MANOV Revealed a significant difference on the five dependent variables (BMI and the four positive personal attributes) among the four health groups (Wilks' Lambda $F=$ 22208.67, $\left.d f=917, p<.01, \mathrm{y}^{2}=.992\right)$. The results indicated the significant main effect for the health group and the adequate level of the effect size. Subsequently, ANOVA revealed a significant mean difference in hope, gratitude, life satisfaction, and subjective happiness among the four health groups $\left(F=88.266, p<.01, \mathrm{\eta}^{2}=\right.$ .223; $F=21.110, p<.01, \mathrm{\eta}^{2}=.064{ }^{\mathrm{F}}=64.47,{ }^{\mathrm{p}}<.01, \mathrm{y}^{2}=.174 ; F=$ 125. 804, $\left.p<.01, \mathrm{y}^{2}=.291\right)$, but not in BMI $\left(F=2.189, p>.05, \mathrm{n}^{2}=\right.$ .007). Accordingly, the follow-up comparisons between each group in the four positive personal attributes were conducted using the Tamhane methods.

The post-hoc comparison (Tamhane method) revealed a significant mean score difference between each group comparison on hope, life satisfaction, and subjective happiness. In contrast, the post-hoc comparison (Tamhane method) yielded significant mean score comparisons between group 1 and 3, group 1 and 4, group 2 and 4, and group 3 and 4, but not between group 1 and 2, group 2 and 3 on gratitude.

\section{Discussion}

The first aim of this study sought to determine a profile of the university students' health, psychological well-beings, and BMI. Overall, this study showed the positive profile of Chinese college students' physical and mental health. The majority of Chinese university students self-reported that they, sometimes and often, felt healthy and energetic, had a good sleep, satisfied with their body weight. More than two-third of the students' BMI was in the normal weight category. Only a small proportion of Chinese university students self-reported that they felt often (13\%) depressed and stressful. Five out of 925 students $(0.5 \%)$ self-reported feeling frequently depressed and stressful.

Consistent with this finding, Bieda et al. [33] reported that Chinese university students $(n=12,524)$ self-reported a higher level of mental health than German university students $(n=4,453)$ and Russian university students $(n=3,806)$. Compared to a growing depression and anxiety concern today facing American university students, the Chinese university students' physical and mental health condition is relatively positive. Field, Diego, Pelaez, Deeds, and Delgado [34] reported that $86 \%$ of the universities in US reported increasing rate of depression.

According to Association for University and College Counseling Center Directors (AUCCCD) annual survey conducted in 2011-
2012 in US, anxiety and depression were the two top mental health concerns among American college students. In lieu of this mental health crisis, a growing number of research studies have shown that building psychological well-being is instrumental to reducing the symptoms of depression and anxiety Gilman et al. [6]; Snyder and Shorey [20]; Snyder et al [19]; Zullig et al. [35]; Zullig, et al. [18]. In this study, the majority of Chinese university students self-reported that they felt somewhat and mostly grateful toward, hopeful for, happy about, and satisfied with their lives. In short, the majority of the Chinese university students self-reported that they had a good to better physical and mental health condition, healthy body weight, and a relatively high level of psychological well-being.

The second aim of this study was to examine the extent to which the four positive constructs of psychological well-being (hope, gratitude, global life satisfaction, global subjective happiness) and BMI collectively and individually contributed to physical and mental health in Chinese university students. Consistent with the previous studies reporting the critical role of positive personal attributes in promoting better physical and mental health Feldman and Sills [36]; Seligman \& C sikszentmihalyi [3]; Wood \& Tarrier [26]; Zullig and White [35], the present study empirically confirmed that BMI and the four positive constructs of psychological wellbeing significantly contributed to the students' physical and mental health.

More importantly, the present study found that the interplay of these constructs was a larger significant contributor to the students' physical and mental health. This present results suggest that the college students' physical and mental health are largely shaped by maintaining a healthy body weight, feeling happy and satisfied about their lives, having hopeful thinking, and showing appreciation for what they have been helped.

Furthermore, the students who were in higher levels of self-rated health reported higher levels of hope, gratitude, life satisfaction, and subjective happiness than the students who were in lower levels of self-rated health. In other words, the higher positive psychological well-being the student has, the more physically and mentally healthy the student is likely to be.

In the past there has been a lack of examination in the interplay of BMI and the four positive personal attributes contributing to physical and mental health in university students, especially in Chinese university students. The unique contribution of this study to positive psychology literature is that having a healthy body weight and building positive personal attributes and virtues are promising, 
effective approaches to develop better physical and mental health and to prevent mental health problems in university students. The results suggest that universities need to creatively design wellness programs and/or centers that dynamically integrate body, mind, and sprit into a seamless unit.

In such wellness programs, not only the students have opportunities to be engaged in a variety of physical activities, sports, and fitness activities for developing and maintaining healthy body weight, but also they participate in mindful physical and fitness activities while learning and building these positive attributes. The students will be instructed and encouraged to apply the positive attributes into their engagement in mindful physical activities. Also, instructors will develop specific intervention strategies for developing, building, and maintaining the positive constructs of psychological well-being within the context of engaging in physical activities and sports. In general, the present results provide empirical evidence for positive attributes-based body-mind intervention strategies for promoting university students mental and physical health.

Among these positive predictors, subjective happiness was the most significant contributor to the university students 'physical and mental health. This finding provided an empirical support for previous studies reporting the paramount role of subjective happiness in promoting physical and mental health Ahmed [37]; Bieda et al. [33]; Cho, Martin, Margrett, MacDonald, \& Poon [38]; Kaczmarek, Bqczkowski, Enko, Baran and Theuns [39]. Subjective happiness is the most salient and enduring positive emotional experience of joy and contentment and subjective appraisal of meaning, purpose, quality, satisfaction, and worthiness of life Lyubomorsky and Lepper [32]; Seligman \& C sikszentmihalyi [3] .

As a result, subjectively happier students are more likely to participate in socially enriched events and to engage in productive and healthy social interactions with others and intellectually challenged activities compared to less happy students Huppert [40]; Kaczmarek et al. [41]; Saricam [42]. Also, happier people are more likely to have positive views of others, events, and life and to maintain positive mental state. Happy people tend to be more functional and productive in coping with normal stresses of life Ahmed [37]; Huppert [40]; Uysal and Satici [43]. In line with the present finding, previous studies reported that happiness was strongly associated with better mental health in university students Salehi, Hajizad, and Bagheri [44]; Sasanpour, Khodabakhshi and Nooryan [45].

The present results show that hope was unique and the second largest significant predictor of good mental and physical health. According to hope theory, hope is stable character strength. Highhope individuals, compare to low-hope individuals, are more likely to have clearly conceptualized goals in general and in specific domains, to develop feasible and alternative pathways to their defined and determined goals, and to initiate their inner drive and sustain their motivation toward achieving the goals even when they are facing obstacles and setbacks in the process of reaching the goals Feldman and Sills [36]; Syner [19]; Synder et al. [46].
In other words, higher hope individuals tend to think, plan, strategize, and drive for attaining their determined goals due to their increased goal-oriented thinking, self-efficacy and motivation. Supporting the hope theory, Nothwehr, Clark, and Perkins [23] found that hope is strongly associated with self-planning and self-monitoring physical activity and health diet behaviors. Furthermore, Scioli, Scioli-Salter, Sykers, Anderson and Fedele [47] found that higher hope college students self-reported feeling physically healthy, engaging in moderate and vigorous exercises more frequently and longer, sleeping adequately, and being less affected by stress and trauma.

Similarly, in a study of examining the role of current hope level in influencing healthy behaviors among 2700 university students, Berg, Ritschel, Swan An and Ahluwalia [48] reported that higher hope university students self-reported engaging in healthy behaviors including more frequent exercising, less frequent smoking, alcohol and high-fat food consumption, and lower incidence of binging drinking. Given the important role of hope in practicing healthy behaviors, hope is an essential construct contributing to good health Feldman and Sills [36]; Nothwehr et al. [23]; Scioli et al. [47].

This study showed that BMI was a negatively significant predictor of health in Chinese university students. Supporting the present finding, VanKim and Nelson [49] found that normalweight university students had significantly better mental health and lower level of perceived stress than the overweight and class I obese students. Further, Vargas, Flores and Robles [50] found that overweight was significantly associated with sleep disturbance in college students, whereas normal weight was not. Moreover, in a longitudinal study examining the correlates BMI and lifestyle, Wilsgaard, Jacobsen and Arnesen [51] reported that persons with lower baseline BMI ate breakfast regularly, while the individuals with higher baseline BMI did not eat breakfast regularly $[52,53]$.

They also found higher BMI was linked to heavy smoking and alcohol consumption. The findings of the previous studies showed that BMI was inversely related to quality of life and healthy lifestyle. This inverse relationship suggests that the healthy body weight the university students possess, the better physical and mental health they have. While the results make unique advancements to the existing literature in positive psychology, the present study has limitations. First, the participants of this study were recruited from one major university. The present results cannot be generalized to other university student population in China. To have a better understanding of psychosocial determinants of physical and mental health among university students, the future study may extend the present study to other universities located in different cities and regions and to different tiered universities.

Second, the cross-section research design of the present study made it impossible for determining any causal effects of positive personal attributes and BMI on physical and mental health. Given the empirical findings of the significant role of positive personal attributes and BMI in contributing to physical and mental health, enhancing the four positive constructs (hope, gratitude, life 
satisfaction, and subjective happiness) and maintaining healthy body weight may be effective intervention strategies for improving physical and mental health among university students. Third, the focus of the present study is not on comparing gender differences in the association of positive personal attributes and BMI with physical and mental health. Future studies may examine this relationship further.

Lastly, the present study is limited to examining the association of the four positive personal attributes and BMI with the physical and mental health. However, how BMI mediates the influence of the four positive personal attributes on the physical and mental health; how each of the four positive personal attributes are related to each other; and how one positive attribute such as gratitude mediates the impact of the other attributes along with BMI should be warranted in future studies. The future findings about the mediating and moderating roles played in the associations may contribute to designing future intervention studies for improving physical and mental health among college students [54,55].

\section{Conclusion}

It was concluded that the state of physical and mental health in university students was largely depended on whether or not they had healthy body weight and positive personal attributes. The better physical and mental health the university students self-rated, the higher level of hope, gratitude, life satisfaction, and subjective happiness the university students self-reported. This study suggests that maintaining healthy body weight and fostering hopeful thoughts, thankful dispositions, life satisfactory, and happiness would be effective intervention strategies for promoting physical and mental health among university students.

\section{References}

1. (2012) National Alliance on Mental Health 2012 mental-healthproblems-facing-college-students.

2. Pedrelli P, Maren N, Yeung A, Zulauf C, Wilens T, et al. (2015) College Students: Mental Health Problems and Treatment Considerations. Academic Psychiatry 39(5): 503-511.

3. Seligman MEP, Csikszentmihalyi M (2000) Positive psychology. American Psychologist 55(1): 5-14.

4. Wood AM, Froh JJ, Geraghty AWA (2010) Gratitude and well-being: A review and theoretical integration. Clinical Psychology Review 30(7): 890-905.

5. Emmons RA, McCullough ME (2003) Counting blessings versus burdens: An Experimentalinvestigation of gratitude and subjective well-being in daily life. Journal of Personality and Social Psychology 84(2): 377-389.

6. Gilman R, Huebner ES, Laughlin JE (2000) A first study of the multidimensional students 'life satisfaction scale with adolescents. Social Indicators Research 52(2): 135-160.

7. Snyder CR (2002) Hope theory: Rainbows in the mind. Psychology Inquiry 13(4): 249-275.

8. Fahey TD, Insel PM, Roth WT, Insel CEA (2017) Fit \& Well: Core Concepts and Labs in Physical Fitness and Wellness. 12 ${ }^{\text {th }}$ Ed. McGraw Hill, Publishers.

9. (2014) World Health Organization (WHO) 2014.

10. Diener E, Suh EM, Lucas RE, Smith HL (1999) Subjective well-being: Three decades of progress. Psychological Bulletin 125(2): 276-302.
11. Diener E, Emmons RA, Larsen RJ, Griffin S (1985) The satisfaction with life scale. Journal of Personality Assessment 49(1): 71-75.

12. Lyubomirsky S (2007) The how of happiness: A scientific approach to getting the life you want. New York, NY: Penguin Press.

13. Lyubomirsky, King, Diener (2005) The benefits of frequent positive affect: Does happiness lead to success? Psychological Bulletin 131(6): 803-855.

14. Dockray S, Steptoe A (2010) Positive affect and psychobiological processes. Neuroscience Biobehavioral Review 35(1): 69-75.

15. O'Connor BP, Crawford MR, Holder MD (2015) An item response theory analysis of the subjective happiness scale. Social Indicators Research 124(1): 249-258.

16. Ash C, Huebner ES (2001) Environmental events and life satisfaction reports of adolescents: A test of cognition mediation. School Psychology International 22(3): 320-336.

17.Zullig KJ, Valois RF, Huebner ES, Oeltmann JE, Drane JW (2001) Relationship between perceived life satisfaction and adolescents' substance abuse. Journal of Adolescent Health 29(4): 279-288.

18. Zullig KJ, Valois RF, Huebner ES, Drane JW (2005) Adolescent healthrelated quality of life and perceived satisfaction with life. Quality of Life Research 14(6): 1573-1584.

19. Snyder CR, Shorey HS (2002) Hope in the classroom: The role of positive psychology in academic achievement and psychology curriculum. Psychology Teacher Network 12: 1-9.

20. Snyder CR, Shorey HS, Cheavens J, Pulvers KM, Adams III VH, et al. (2002) Hope and academic success in college. Journal of Educational Psychology 94(4): 820-826.

21. Snyder CR, Lopez SJ, Shorey HS, Rand KL, Feldman DB (2003) Hope theory, measurements, and applications to school psychology. School Psychology Quarterly 18(2): 122-139.

22. Snyder CR, Harris C, Anderson JR, Holleran SA, Irving LM, et al. (1991) The will and the ways: Development and validation of an individualdifferences measure of hope. Journal of Personality and Social Psychology 60(4): 570-585.

23. Nothwehr F, Clark DO, Perkins A (2013) Hope and the use of behavioral strategies relatedto diet and physical activity. Journal of Human Nutrition and Dietetics 26(1): 159-163.

24. Onwuegbuzie AJ, Snyder CR (2000) Relations between hope and graduate students' studying and test-taking strategies. Psychological Reports 86: 803-806.

25. McCullough ME, Tsang J, Emmons RA (2004) Gratitude in intermediate affective terrain: Links of grateful moods to individual differences and daily emotional experience. Journal of Personality and Social Psychology 86(2): 295-309.

26. Wood AM, Tarrier N (2010) Positive Clinical Psychology: A new vision and strategy for integrated research and practice. Clinical Psychology Review 30(7): 819-829.

27. McCullough ME, Emmons RA, Tsang J (2002) The grateful disposition: A conceptual and empirical topography. Journal of Personality and Social Psychology 82(1): 112-127.

28. Corica F, Corsonello A, Apolone G, Mannucci E, Lucchetti M, et al. (2008) metabolic syndrome, psychological status and quality of life in obesity: The QUOVADIS study. International Journal of Obesity 32(1): 185-191.

29. Carr D, Friedman MA, Jaffe K (2007) Understanding the relationship between obesity and positive and negative affect: The role of psychosocial mechanisms. Body Image 4(2): 65-177.

30. Bookwala J, Boyar J (2008) Gender, excessive body weight, and psychological well-being in adulthood. Psychology of Women Quarterly 32: 188-195. 
31. Chen LH, Chen MY, Kee YH, Tsai YM (2009) Validation of the gratitude questionnaire (GQ) in Taiwanese undergraduate students. Journal of Happiness Studies 10(6): 655-664.

32. Lyubomirsk S, Lepper HS (1999) A measure of subjective happiness: Preliminary reliability and construct validation. Social Indicators Research 46: 137-155.

33. Bieda A, Hirschfeld G, Schönfeld P, Brailovskaia J, Zhang XC, et al. (2016) Universal Happiness? Cross-Cultural Measurement Invariance of Scales Assessing Positive Mental Health. Psychological Assessment. 29(4): 408421.

34. Field T, Diego M, Pelaez M, Deeds O, Delgado J (2012) Depression and related problems in university students. College Student Journal 46 : 198-202.

35. Zullig KJ, White RJ (2011) Physical activity, life satisfaction, and selfrated health of middle school students. Applied Research Quality Life 6(3): 277-289.

36. Feldman DB, Sills JR (2013) Hope and cardiovascular health-promoting behavior: Education alone is not enough. Psychology and Health 28(7): 727-745.

37. Ahmed S (2017) Mental health stigma and subjective happiness. Journal of Psychology and Clinical Psychiatry 7(1): 1-4.

38. Cho J, Martin P, Margrett J, MacDonald M, Poon LW (2011) The relationship between physical health and psychological well-being among oldest-old adults. Journal of Aging Research pp. 1-8.

39. Kaczmarek LD, Bqczkowski B, Enko J, Baran B, Theuns P (2014) Subjective well-being as a mediator for curiosity and depression. Polish Psychological Bulletin 45(2): 200-204.

40. Huppert FA (2009) Psychological well-being: Evidence regarding its causes and consequences. Applied Psychology: Health and Well-being 1: $137-164$

41. Kaczmarek LD, Bqczkowsk B, Enko J, Baran B, Theuns P (2014) Subjective well-being as a mediator for curiosity and depression. Polish Psychological Bulletin 45(2): 200-204.

42. Saricam H (2014) Subjective happiness and hope. Universitas Psycholgica 14(2): 685-694.

43. Uysal R, Satici SA (2014) The mediating and moderating role of subjective happiness in the relationship between vengeance and forgiveness. Educational Science: Theory and Practice 14(6): 2097-2105.
44. Salehi M, Hajizad M, Bagheri H (2011) The relation between religious notion with students' happiness and mental well-being. World Applied Sciences Journal 14(10): 1537-1540.

45. Sasanpour M, Khodabakhshi M, Nooryan K (2012) The relationship between emotional intelligence, happiness and mental health in students of medical sciences of Isfahan. International Journal of Collaborative Research on Internal Medicine \& Public Health 4(9): 1-7.

46. Snyder CR, Sympson SC, Ybasco FC, Borders TF, Babyak MA, et al. (1996) Development and validation of the State Hope Scale. Journal of Personality and Social Psychology 70(2): 3121-3335.

47. Scioli A, Scioli-Salter ER, Sykes K, Anderson C, Fedele M (2016) The positive contributions of hope to maintaining and restoring health: An integrative, mixed-method approach. Journal of Positive Psychology 11: 135-148.

48. Berg CJ, Ritschel LA, Swan DW, An LC, Ahluwalia JS (2011) The role of hope in engaging in healthy behaviors among college students. American Journal of Health Behavior 35(4): 402-415.

49. VanKim NA, Nelson TF (2013) Vigorous physical activity, mental health, perceived stress, and socializing among college students. American Journal of Health Promotion 28(1): 7-15.

50. Vargas PA, Flores M, Robles E (2014) Sleep Quality and Body Mass Index in College Students: The Role of Sleep Disturbances. Journal of American College Health 62(8): 534-541.

51. Wilsgaard T, Jacobsen BK, Arnesen E (2005) Determining Lifestyle Correlates of Body Mass Index using Multilevel Analyses: The Troms $\varnothing$ Study, 1979-2001. American Journal of Epidemiology 162(12): 11791182.

52. Magaletta PR, Olive JM (1999) The hope construct, will, and ways: their relations with self-efficacy, optimism, and general well-being. Journal of Clinical Psychology 55(5): 539-551.

53. Saricam H (2014) Subjective happiness and hope. Universitas Psycholgica 14(2): 685-694.

54. International Journal of Collaborative Research on Internal Medicine \& Public Health 4(9): 1614-1620.

55. WHO Expert Consultation (2004) Appropriate body-mass index for Asian populations and its implications for policy and intervention strategies. Lancet 363(9403): 157-163.

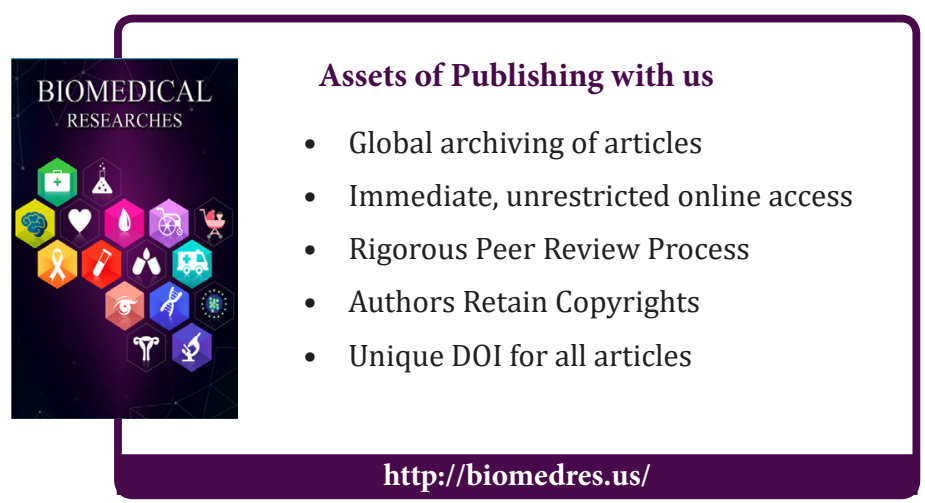

